Annals of International Medical and Dental Research

E-ISSN: 2395-2822 | P-ISSN: 2395-2814

Vol-8, Issue-2 | March-April 2022

DOI: 10.53339/aimdr.2022.8.2.11

Page no- 70-78 | Section- Research Article (Pediatrics)

\title{
Bone Marrow Aspiration Findings in Hematological Disorders in Children
}

\author{
Jaswir Singh1, Manpreet Sodhi2*, Ramesh Kundal ${ }^{3}$, Pooja H.M ${ }^{4}$
}

1Professor, Department of Pediatrics, Govt. Medical College, Patiala, Punjab, India.

Email ID: Jaswir-singh@yahoo.com,

Orcid ID: 0000-0003-3446-0964

${ }^{2}$ Assistant Professor, Department of Pediatrics, Govt. Medical College, Patiala, Punjab, India.

Email ID: Kaursodhi2007@gmail.com, Orcid ID: 0000-0003-2001-1615

3Professor, Department of Pathology, Govt. Medical College, Patiala, Punjab, India.

Email ID: kumarkundalramesh@gmail.com, Orcid ID: 0000-0001-7893-9163

Junior Resident, Department of Pediatrics, Govt. Medical College, Patiala, Punjab, India. Email ID: Poojahm1812@gmail.com, Orcid ID: 0000-0003-2837-8104

${ }^{*}$ Corresponding author

Received: 17 November 2021

Revised: 07 January 2022

Accepted: 17 January 2022

Published: 18 February 2022

\begin{abstract}
Background: Primary objective was to study bone marrow aspiration(BMA) findings in hematological disorders in children with secondary objective to find correlation between peripheral blood film (PBF) findings with BMA. Material \& Methods: It was observational and cross-sectional study conducted on 65 children in age group of 1-18 yrs admitted to Pediatrics Department of Government Medical College, Patiala over period of $1 \mathrm{yr}$. Inclusion criteria was based on clinical and laboratory parameters. Children were of anaemia, leucopenia and pancytopenia. Complete hemogram, reticulocyte count, PBF smear and bone marrow aspiration were done. The data was analyzed using IBM Statistical Packages for Social Sciences SPSS software version 22. Results: The mean age of study population was $10.39 \pm 6.29 y$ yrs. $93.8 \%$ children presented with pallor followed by fever in $84.6 \%$ and lethargy in $66.2 \%$. 62 children were severely anaemic, 33 had bicytopenia, 23 children had pancytopenia. Bone marrow was hypercellular in $59(90.8 \%)$ children. $40(61.5 \%)$ children had megaloblastic anaemia on BMA followed by dimorphic anaemia in 8, Idiopathic thrombocytopenic purpura in 6 children. 4 children each had Megaloblastic anaemia with gelatinous transformation and micronormoblastic anaemia. 2 children had acute lymphatic leukemia and one had aplastic anaemia. The predominant PBF was dimorphic in 30 children, out of whom 22 had megaloblastic anaemia and 8 had dimorphic anaemia on BMA. Conclusions: Bone marrow was megaloblastic in majority $(61.5 \%)$ of children. There was no significant association found between PBF findings and bone marrow diagnosis.
\end{abstract}

Keywords:- Anaemia, Bicytopenia, Pancytopenia, Megaloblastic anaemia.

\section{INTRODUCTION}

Unlike adults, the spectrum of hematological disorders in children is very wide ranging from very common conditions like iron deficiency anaemia to rare congenital disorders like Blackfan Diamond Syndrome and Fanconi anaemia and to very serious conditions like leukemia. These common hematological disorders of childhood have the potential to cause not only acute illness but chronic medical problems, particularly in growing children.[1,2]

A number of studies on anaemia in children have been conducted however they focussed more on prevalence and severity of the disease. And further there are limited studies on hematololgical disorders in the age group 1 to 18 years. 
Annals of International Medical and Dental Research

E-ISSN: 2395-2822 | P-ISSN: 2395-2814

Vol-8, Issue-2 | March-April 2022

DOI: 10.53339/aimdr.2022.8.2.11

Page no- 70-78 | Section- Research Article (Pediatrics)

Child may present with anaemia, leucopenia, thrombocytopenia even pancytopenia of varied etiologies. Bone marrow aspiration (BMA) though invasive is available at most of centres, offer the advantage of exact diagnosis. More so serum assays of most of vitamins and micronutrients/minerals are costly and not available commonly. So keeping this in mind, the study was planned to see how bone marrow aspiration vary in different hematological disorders with secondary objective of establishing correlation between peripheral blood film (PBF) findings with BMA.

\section{MATERIAL AND METHODS}

This observational and cross-sectional study was conducted in the Department of Pediatrics, Rajindra hospital, Patiala. Total of 65 patients admitted in the pediatric wards between the age group of 1 to 18 years over a period of 12 months from May 2019 to April 2020 were included in the study. The study was approved by institutional ethical committee vide letter no. 8 (109) 2019 /7856 dated 5/4/2019. Methodology for this study was also approved by ethical committee. Informed consent was taken from parents of the patients as per institutional ethical committee.

\section{Inclusion criteria}

Following were clinical and laboratory criteria in children age group 1 to 18 years

Clinical: Pallor with or without hepatosplenomegaly, with or without petechiae and purpura
Laboratory: Any one of the following laboratory criteria:

1. $\mathrm{Hb}<7 \mathrm{gm} / \mathrm{dl}$ in $1-5$ years, $<8 \mathrm{gm} / \mathrm{dl}>5$ years. [3]

2. Bicytopenia

3. Pancytopenia

4. Abnormal cells on PBF

\section{Exclusion Criteria}

1. Hematological abnormalities secondary to the underlying infectious and systemic diseases.

2. Children diagnosed as thalassemia and other hemolytic blood disorders.

Cytopenia- defined as the reduction in any of the cellular elements of blood i.e., RBCs, WBCs or platelets. Cytopenia is taken as hemoglobin $<10 \mathrm{gm} / \mathrm{dl}$ and/or TLC $<4000 / \mathrm{cmm}$ and/or platelets $<1$ lakh/cmm.

Bicytopenia- defined as the reduction in any of the two cell lines.

Pancytopenia- defined as the reduction in all the three cell lines.[4,5]

\section{Complete hemogram}

Blood Sample (approx. $2 \mathrm{ml}$ ) was dispensed into vials containing EDTA(Ethylenediamine tetra acetic acid) anticoagulant. These were subjected to CBC (Complete Blood Count) performed by an automated analyzer. The blood was well mixed and placed on a rack in the analyser. The instrument counted the number and type of different cells within the blood and results were printed out that included hemoglobin $(\mathrm{Hb})$, red blood cell (RBC), hematocrit (HCT), Mean corpuscular volume $(\mathrm{MCV})$, mean corpuscular hemoglobin 
Annals of International Medical and Dental Research

E-ISSN: 2395-2822 | P-ISSN: 2395-2814

Vol-8, Issue-2 | March-April 2022

DOI: 10.53339/aimdr.2022.8.2.11

Page no- 70-78 | Section- Research Article (Pediatrics)

$(\mathrm{MCH})$, Mean corpuscular hemoglobin concentration $(\mathrm{MCHC})$ red cell distribution width (RDW), White blood cells (WBC), thrombocyte(platelet),

granulocytes,lymphocytes and monocytes.

Reticulocyte Count: Blood sample was collected like same as $\mathrm{CBC}$ and further counted using manual method under microscope or BCB method (Brilliant cresyl blue)

Peripheral blood smear: Blood sample was collected like same as CBC and the 'push' (wedge) or 'cover slip method' was used. Smear was obtained and dried. Dried smear was fixed with absolute methanol or ethyl alcohol and stained with Leishman stain composed of polychrome methylene blue and eosin and then was viewed under microscope.

Bone marrow aspiration: It was done using Salah's $16 \mathrm{G}$ bone marrow aspiration needle. Site - PSIS (Posterior Superior Iliac Spine) was the most preferred followed by ASIS (Anterior Superior Iliac Spine). Method - Under all aseptic conditions, local anaesthesia (inj. 2\% lignocaine) was infiltrated into skin, subcutaneous tissue and periosteum. Then Salah's bone marrow aspiration needle was inserted through the skin, subcutaneous tissue and bone marrow with slight rotating motion. Entrance of needle into marrow cavity was sensed as a slight give away or increase in speed of needle advancement. The needle obturator was removed and the needle was attached to a $20 \mathrm{ml}$ syringe. Aspiration of marrow was achieved by rapid suctioning with a syringe so that 0.2 to $2 \mathrm{ml}$ of bloody fluid is obtained. The films were prepared immediately by placing the aspirated material on a slanting slide and was drawn along where the trails of dislodged bone marrow cells were present. These films were air dried and then stained with Leishman's stain and were mounted with DPX (mixture of distyrene, plasticizer and xylene). In cases of dry tap, the smear were made from the material at the tip of the needle. Stain used was Leishman's stain.Staining method - After air drying the film, the slide was flooded with Leishman's stain. After 2 mins, double the volume of water was added and film was stained for 5 to 7 mins. Then the film was washed in a stream of buffered water until it acquired pinkish tinge (upto 2 mins). After that, the back of slide was wiped clean and set upright to dry.

A detailed clinical history and general physical and systemic examination will be done on predefined proforma. Statistical methods: The data was processed and analyzed using the IBM Statistical Packages for Social Sciences, SPSS software version 22. Shapiro-Wilk test was used to test for normality of the data. Results of continuous measurements was measured as frequency mean and standard deviation. Results of categorical measurements was measured as number (\%). Chisquare test was used for comparison between different types of measurements.

Sample size: The sample size is calculated based on the results of a previous study by Rawat $A$ et al, $[6]$ using statistical $G$ power software. $\chi^{2}$ tests - Variance: Difference from constant (one sample case).

\section{Analysis}

A priori: Compute required sample size

Tail(s) $=$ One

$a$ err prob $=0.05$ 
Annals of International Medical and Dental Research

E-ISSN: 2395-2822 | P-ISSN: 2395-2814

Vol-8, Issue-2 | March-April 2022

DOI: 10.53339/aimdr.2022.8.2.11

Page no- 70-78 | Section- Research Article (Pediatrics)

Power $(1-\beta$ err prob $)=0.80$

Lower critical $\chi^{2}=66.33$

Upper critical $\chi^{2}=66.33$

$\mathrm{df}=49$

Total sample size $=50$

Actual power $=0.80$

The total sample calculated is 50 for $90 \%$ CI, $80 \%$ power.

\section{RESULTS}

The study was conducted on 65 children. Majority (37) of patients were female (56.9\%) and rest (28) were male $(43.1 \%)$. Majority of children i.e. 25 were in age group of 15-18yrs $(38.5 \%)$ followed by 21 patients in 1-5 yrs $(32.2 \%), 10$ patients in 6-11 yrs $(15.4 \%)$ and 9 patients in 12-14 yrs (13.8\%)age group respectively. Mean age of study population was $10.39 \pm 6.29$ yrs.

93.8\% children presented with pallor followed by fever in $84.6 \%$, lethargy (66.2\%)and knuckle hyperpigmentation (58.5\%) as shown in figure 1. Hepatosplenomegaly was observed in 12 patients $(18.46 \%)$. Only one patient had bone pain. All children were anaemic according to WHO standards. [3] Out of these, 62 were severely anaemic and 3 were moderately anaemic. Mean Haemoglobin $(\mathrm{Hb})$ in $\mathrm{gm} / \mathrm{dl}$ was 4.95 \pm 1.59 (Range=2.5-8.5). Mean Total Leucocyte Count (TLC) in cumm was 4668.77 \pm 2713.57 (Range=1200-12,600). Mean Platelet count in cumm was $88107.68 \pm 80412.83$ (Range $=3000-4,87000$ ). Mean Reticulocyte count was $1.35 \pm 0.68$ (Range=0.1-3.50).

Bicytopenia was obsereved in 33 children and 23 had pancytopenia.Out of 33 children with bicytopenia, 10 had anaemia with leucopenia $(15.6 \%)$ and 23 had anemia with thrombocytopenia (35.9\%). Bone marrow was hypercellular in $59(90.7 \%)$ children. It was normocellular in $5(7.7 \%)$ and hypocellular in one patient. Bone marrow lineage was erythroid hyperplasia in 59 (90.7\%), myeloid hyperplasia in $3(4.7 \%)$ and normocellular in 2 children $(3.1 \%)$.

The bone marrow aspiration findings in the present study are shown in [Table 1]. Majority of children $(61.5 \%)$ had megaloblastic anaemia (MA). When it was segregated into anaemia, bicytopenia and pancytopenia, even then Megaloblastic Anaemia was predominant finding [Table 2]. In comparison of bicytopenia, Megaloblastic anaemia was more in children with anaemia with thrombocytopenia than bicytopenia due to anaemia and leucokopenia, though statistically the difference was non significant $(p>0.05)$ as shown in [Table 3].

The predominant PBF finding in study was micro-macro and ovalocytes (30 children) as shown in [Table 4]. When PBF findings were associated with BMA findings, it was found that when PBF has purely macro-ovalocytes as well as along with hyperpigmented neutrophils (HSN), BMA was showing MA only. When PBF was having micro in addition to macro-ovalocytes, though predominant BMA was MA, but there were few cases of dimorphic anaemia (DA) also [Table 4]. There was no significant association found between the PBF findings and bone marrow diagnosis ( $p$ value $=0.05)$. 
Annals of International Medical and Dental Research E-ISSN: 2395-2822 | P-ISSN: 2395-2814

Vol-8, Issue-2 | March-April 2022

DOI: 10.53339/aimdr.2022.8.2.11

Page no- 70-78 | Section- Research Article (Pediatrics)

Table 1: Bone Marrow Aspiration Findings In The Study

\begin{tabular}{|l|c|c|}
\hline Diagnosis & Number & Percentage \\
\hline Acute Lymphocytic Leukaemia & 2 & 3.1 \\
\hline Aplastic anaemia & 1 & 1.5 \\
\hline Dimorphic anaemia & 8 & 12.3 \\
\hline Idiopathic Thrombocytopenic Purpura & 6 & 9.2 \\
\hline Megaloblastic anaemia & 40 & 61.5 \\
\hline Megaloblastic anaemia +Gelatinous Transformation & 4 & 6.2 \\
\hline Micro-normoblastic anaemia & 4 & 6.2 \\
\hline
\end{tabular}

Table 2: Distribution Of Bone Marrow Diagnosis In Relation To Hematological Disorders

\begin{tabular}{|l|l|l|l|l|l|l|l|l|}
\hline Hematological Disorders & ALL & AA & DA & ITP & MA & MA+GMT & MNA & Total \\
\hline Severe anaemia & 2 & 1 & 8 & 6 & 38 & 4 & 3 & 62 \\
\hline Bicytopenia & 2 & 0 & 5 & 5 & 18 & 3 & 0 & 33 \\
\hline Pancytopenia & 0 & 1 & 2 & 1 & 19 & 0 & 0 & 23 \\
\hline
\end{tabular}

Abbreviations: ALL=Acute Lymphatic Leukaemia, AA=Aplastic anaemia, DA=Dimorphic anaemia, ITP=Idiopathic Thrombocytopenic Purpura, MA=Megaloblastic anaemia, MA+GMT=Meagloblastic anemia with gelatinous transformation, $\mathrm{MNA}=$ Micronormoblastic anaemia

Table 3: Association Of Bicytopenia And Bone Marrow Diagnosis

\begin{tabular}{|l|l|l|l|l|l|l|l|l|l|}
\hline Bicytopenia & \multicolumn{4}{|c|}{ Diagnosis } & Total & P value \\
\hline & ALL & AA & DA & ITP & MA & MA+GMT & MNA & & \\
\hline Anaemia and Leukopenia & 0 & 0 & 4 & 0 & 6 & 0 & 0 & 10 & 0.06 \\
$\begin{array}{l}\text { Anaemia and } \\
\text { Thrombocytopenia }\end{array}$ & 2 & 0 & 1 & 5 & 12 & 3 & 0 & 23 & \\
\hline
\end{tabular}

Table 4: Association Of Peripheral Blood Film(PBF) Findings With Bone Marrow Diagnosis

\begin{tabular}{|l|l|l|l|l|l|l|l|l|}
\hline PBF Findings & \multicolumn{9}{|c|}{ Diagnosis } & Total & P value \\
\hline & ALL & AA & DA & ITP & MA & MA+GMT & MNA & \\
\hline Atypical cells & 2 & 0 & 0 & 0 & 0 & 0 & 0 & 2 \\
\hline Macrocytes +Ovalocytes & 0 & 0 & 0 & 0 & 9 & 0 & 0 & 9 \\
\hline $\begin{array}{l}\text { Macrocytes } \\
\text { +Ovalocytes+HSN }\end{array}$ & 0 & 0 & 0 & 0 & 11 & 2 & 0 & 13 \\
\hline $\begin{array}{l}\text { Micro+Macro+Ovalo } \\
\text { Cyte }\end{array}$ & 0 & 0 & 8 & 0 & 20 & 2 & 0 & 30 \\
\hline Micro +Normocytes & 0 & 1 & 0 & 2 & 0 & 0 & 4 & 7 \\
\hline Normocytes & 0 & 0 & 0 & 4 & 0 & 0 & 0 & 4 \\
\hline Total & 2 & 1 & 8 & 6 & 40 & 4 & 4 & 65 \\
\hline
\end{tabular}

Abbreviation: HSN Hyersegmented Neutrophils 
Annals of International Medical and Dental Research

E-ISSN: 2395-2822 | P-ISSN: 2395-2814

Vol-8, Issue-2 | March-April 2022

DOI: 10.53339/aimdr.2022.8.2.11

Page no- 70-78 | Section- Research Article (Pediatrics)

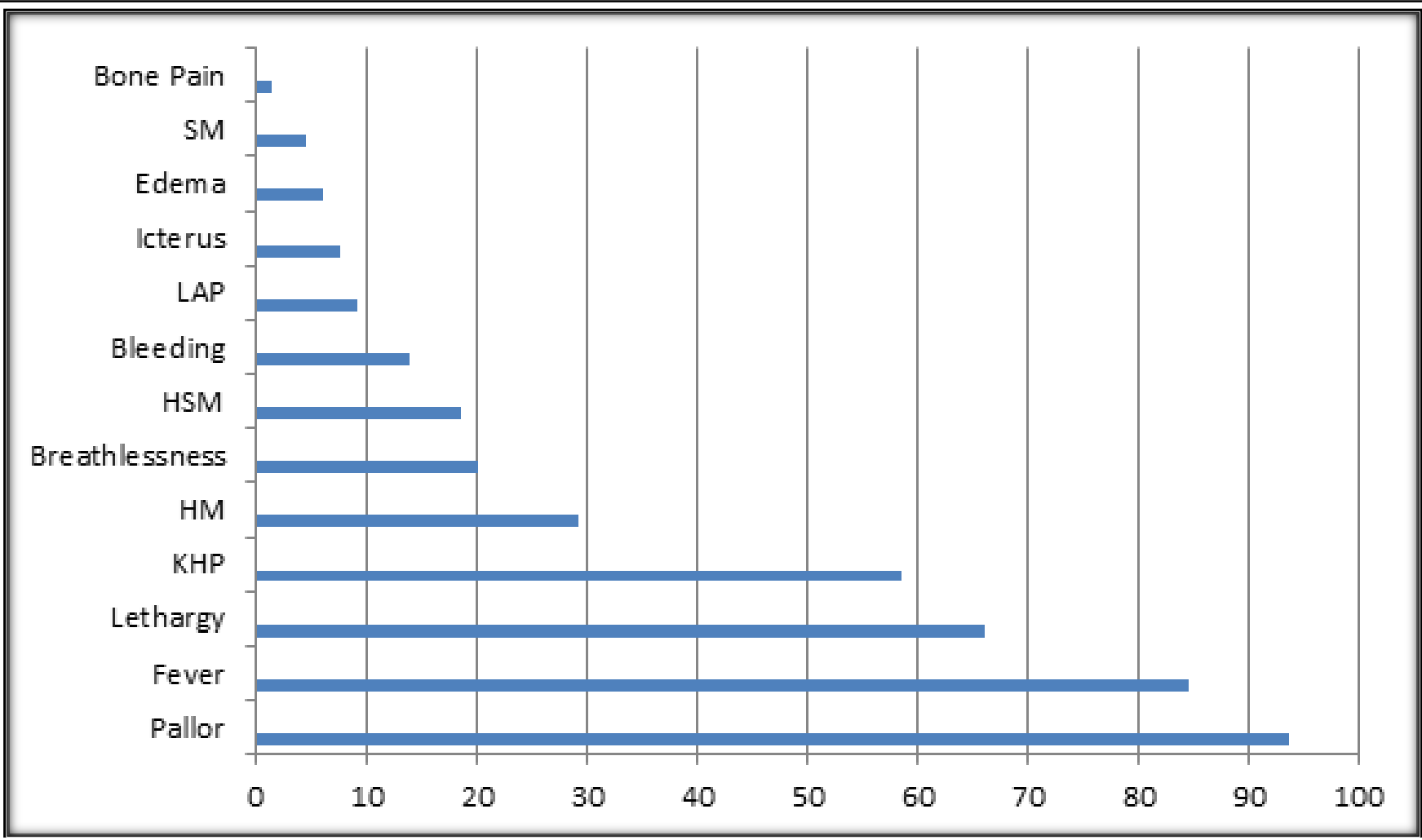

Figure 1: Distribution of Children According to Clinical Features. Abbrevations: KHP=Knuckle Hyperpigmentation, HM=Hepatomegaly, HSM=Hepatosplenomegaly, LAP=Lymphadenopathy, SM=Splenomegaly]

\section{DISCUSSION}

In the present study, maximum number of children were in age group of 15 to 18 yrs $(38.5 \%)$ followed by 1 to 5 yrs $(32.2 \%)$. The age disrtribution in our study was comparable to the study conducted by Rawat et al,[6] that showed $56 \%$ of patients in the range of 11 to 18 yrs.However lower age predominance has also been observed by Prakash et al, [7] and Ayub et al, $[8]$ where it was $<5$ yrs.

There was female predominance with male to female ratio of $1: 1.3$. It was similar to studies done by Ayub et al,[]ㅡ and Tufail et al,[]ㅜ which showed male to female ratio of 1:1.1and 1:1.31 repectively. In most of other studies, male predominance was noted. $[10,11]$ The reason might be social issues, depriving the female children from their nutritional demands.Pallor was seen in $93.8 \%$ of children followed by fever in $84.6 \%$ and lethargy in $66.2 \%$ in present study which is similar to studies done by Gul Z etal and Rasheed J etal.[12,13] Though generalized weakness was most common presenting complaint $(90.7 \%)$ followed by weight loss (80.95\%) and fever(69.04\%) in study done by Chand $R$ et al.11] This could be due to fact that in our study majority of children were severely anaemic who came with fever and half the number of patients were having leukopenia who came with complains of fever. Majority of children 
Annals of International Medical and Dental Research

E-ISSN: 2395-2822 | P-ISSN: 2395-2814

Vol-8, Issue-2 | March-April 2022

DOI: 10.53339/aimdr.2022.8.2.11

Page no- 70-78 | Section- Research Article (Pediatrics)

$\mathbf{( 9 0 . 8 \% )}$ in present study had hypercellular marrow similar to that reported by Javalgi AP et al,[14] Anaemia was seen in all children in present study as pallor was one of the criteria for inclusion in the study, whereas 33 children (50.7\%) had bicytopenia and 23 (35.4\%) had pancytopenia, which is similar to that observed by Ayub et al,[8] with anaemia in $100 \%$, bicytopenia in $45 \%$ and pancytopenia in $42.5 \%$. Rawat $A$ et al,[6] also had anaemia in their study to tune of $86 \%$.

In the present study, predominant RBC morphology was dimorphic i.e.microcytes and macro-ovalocytes in $46.2 \%$ followed by macroovalocytes with HSN in $20 \%$, only macroovalocytes in $13.8 \%$. Dagdia KS et al,[] also had predominant macrocytic picture followed by normocytic anaemia, microcytic anaemia and dimorphic anaemia in peripheral smear examination. In contrary, it was normocytic normochromic followed by macrocytic normochromic and microcytic hypochromic in study by Gupta A et al.[15]

In our study, dividing the causes into neoplastic and non - neoplastic on BMA, $3 \%$ of patients had neoplastic causes and 97\% had non-neoplastic causes.Similar were findings by Memon $S$ et al,[16] who had neoplastic causes in $17.4 \%$ and non -neoplastic causes in $82.6 \%$ on the contrary to that of Tufail A et al,[9] who reported malignant cases to being more than non -malignant cases.

Majority of the patients in our study had megaloblastic anaemia on BMA in all three groups of hematological disorders. 38 patients who had megaloblastic anaemia, presented with severe anaemia followed by pancytopenia in 19 patients and bicytopenia in 18 patients.
Megaloblastic anaemia was predominant finding on BMA in our study as was also reported by various authors in their studies. $[8,11,17,18,19]$ Though aplastic anaemia was also found to be predominant in studies by Gupta $V,[16]$ and Menon et al.[20] This could be explained by different population being studied. The second predominant cause was dimorphic anaemia in present study as also observed by Chand $\mathrm{R}$ et al.[11] Megaloblastic anaemia with gelatinous malformation was seen in 4 cases in present study, its cause could be nutritional deficiency as observed by Khera R etal.[21]

When association was studied between PBF and BMA findings, in present study with dimorphic picture on PBF had megaloblastic anaemia on BMA, with $2^{\text {nd }}$ common picture of macro-ovalocytes with hypersegmented neutrophils also had megaloblastic anaemia.It is similar to observed by Pereira et al,[22] in their study, 21 out of 48 cases were found to be pure megaloblastic anaemia where macroovalocytosis with anisopoikilocytosis was seen in all patients and hypersegmented neutrophils were found to be main feature.

\section{CONCLUSIONS}

In hematological disorders in children ,bone marrow was hypercellular with erythroid hyperplasia in majority $(90.7 \%)$. It was megaloblastic in majority of children followed by dimorphic anaemia. PBF was dimorphic in majority. There was no significant association between PBF findings with bone marrow diagnosis.

Contributors: Dr Jaswir Singh conceptualised and designed the study. Dr. Manpreet Sodhi 
Annals of International Medical and Dental Research

E-ISSN: 2395-2822 | P-ISSN: 2395-2814

Vol-8, Issue-2 | March-April 2022

DOI: 10.53339/aimdr.2022.8.2.11

Page no- 70-78 | Section- Research Article (Pediatrics)

did the data analysis and drafted the manuscript. Dr. Ramesh Kundal supervised the execution of study. Dr. Pooja H.M helped in execution of study and collected the data. All the authors have read and approved the final version of manuscript.

\section{REFERENCES}

1. Rahim F, Ahmad I, Islam S, Hussain M, Khattak TAK, Bano Q. Spectrum of hematological disorders in children observed in 424 consecutive bone marrow aspirations/ biopsies. Pak J Med Sci. 2005;21(4):433-436.

2. Pudasaini S, Prasad KBR, Rauniyar SK, Shrestha R, Gautam K, Pathak R, et al. Interpretation of bone marrow aspiration in hematological disorder. J Path Nepal. 2012;2:309-312.

3. Aburto NJ, Rogers L, De-Regil LM, Kuruchittham V, Rob G, Arif R, et al. An evaluation of a global vitamin and mineral nutrition surveillance system. Arch Latinoam Nutr. 2013;63(2):105-13. PMID: 24934066.

4. Edmondson R, Broglie JJ, Adcock AF, Yang L. Three-dimensional cell culture systems and their applications in drug discovery and cell-based biosensors. Assay Drug Dev Technol. 2014;12(4):207-218. doi:10.1089/adt.2014.573

5. Waris R, Shahid G, Khalid ST, Riaz A, Rehman A. Aetiology of cytopenias in children admitted to a tertiary care hospital. JIMDC. 2017;6(2):104-109.

6. Rawat A, Mamgain V, Chandra S, Kalra BP. Clinico hematological profile of pancytopenia in pediatric patients: an institutional experience in North Himalayan region of India. Int J Res Med Sci. 2020;8(2): 726-729.

7. Prakash A, Kumar A, Awasthi S, Dutta S, Mittal A. Clinicopathological pattern of anemia in children in age group upto 18 year. Int J Med Res Prof. 2018;4(1);262-265.

8. Ayub T, Khan FU. Prevalence of megaloblastic anaemia in a paediatric unit. Gomal J Med Sci.2009;7(1): 62-64.
The authors have no competing interests to declare that are relevant to content of this study. No funding was received for conducting the study. There are no conflicts of interest (both financial as well as non-financial) to disclose by authors.

9. Tufail A, Hashmi MA, Ahmad I, Butt MA. ClinicoEtiological Spectrum of Pancytopenia in Children Presenting in Allied Hospital, Faisalabad. Ann Punjab Med Coll. 2017;11(2):126-131.

10. Naseem S, Varma N, Das R, Ahluwalia J, Sachdeva MU, Marwaha RK. Pediatric patients with bicytopenia/pancytopenia: review of etiologies and clinico-hematological profile at a tertiary center. Indian J Pathol Microbiol. 2011 Jan-;54(1):75-80. doi: 10.4103/0377-4929.77329.

11. Chand R, Singh N. Clinic-etiological profile of pancytopenia in children: a tertiary care centerbased study of Kumaun region, India. Int J Contemp Pediatr. 2018 ;5(6):2173-2177.

12. Gul Z, Ahmad S, Jan AZ, Liaqat F, Khan GA. Spectrum of hematological diseases in pediatric patients presenting with anemia based on bone marrow examination. Gomal J Med Sci. 2014; 12:6063.

13. Rasheed J, Urooj S, Bashir R, Khalid M, Zafar F. Cytopenias in children: clinical, hematological and etiological profile. Isra Med J. 2019; 11(3): 137-140.

14. Javalgi AP, Dombale VD. Clinico Hematological Analysis of Pancytopenia: A Bone Marrow Study. Nat J Lab Med. 2013;2(4):12-17.

15. Gupta A, Bhatnagar R, Prasad PL. Peripheral cytopenia in children: a hospital-based study. Int J Contemp Pediatr. $2020 ; 7(1): 84-89$.

16. Memon S, Shaikh S, Nizamani MA. Etiological spectrum of pancytopenia based on bone marrow examination in children. J Coll Phy and Sur Pak. 2008; Vol.18(3): 163-7.

17. Sharif M, Masood N, Haq MZ, Dodhy MA, Asghar RM. Etiological spectrum of pancytopenia/bicytopenia in children 2 months to 12 years of age. J Rawalpindi Med Coll. 2014;18(1):61-64. 
Annals of International Medical and Dental Research

E-ISSN: 2395-2822 | P-ISSN: 2395-2814

Vol-8, Issue-2 | March-April 2022

DOI: 10.53339/aimdr.2022.8.2.11

Page no- 70-78 | Section- Research Article (Pediatrics)

18. Hans D, Naz N, Sharma P, Suri J, Gupta D. Pancytopenia in children clinical and haematological evaluation. Indian J Pathol Oncol. 2020;7(2):266-268.

19. Sonal B, Priyanka P, Seema M. Clinico-etiological profile of pancytopenia in paediatric patients with special reference to bone marrow examination: A tertiary care centre-based study. Int J Clin and Diag Pathol.2020;3(3):307-310.

https://doi.org/10.33545/pathol.2020.v3.i3e.301

20. Gupta V, Tripathi S, Tilak V, Bhatia BD. A study of clinico-haematological profiles of pancytopenia in children. Trop Doct. 2008;38(4):241-3. doi: 10.1258/td.2008.070422.

21. Khera R, Goel G, Singh T. Gelatinous marrow transformation (GMT): a disease or a symptom of underlying disorders. Int $\mathrm{J}$ Health Sci Res. 2018;8(6):60-64.

22. Pereira AS, Dias A. Hematological Analysis of Pancytopenia: A Prospective Study. Int J Sci Study 2016;4(4):71-78.

Source of Support: Nil, Conflict of Interest: None declared 